Mathématiques et sciences humaines
Mathematics and social sciences

135 | Automne 1996

Varia

\title{
Les problèmes de la statistique
}

The problems of statistics

\section{Georges-Théodule Guilbaud}

\section{OpenEdition}

Journals

Édition électronique

URL : http://journals.openedition.org/msh/2729

DOI : $10.4000 /$ msh.2729

ISSN : $1950-682$

\section{Éditeur}

Centre d'analyse et de mathématique sociales de l'EHESS

\section{Édition imprimée}

Date de publication : 1 septembre 1996

ISSN : 0987-6936

\section{Référence électronique}

Georges-Théodule Guilbaud, "Les problèmes de la statistique », Mathématiques et sciences humaines [En ligne], 135 | Automne 1996, mis en ligne le 10 février 2006, consulté le 23 juillet 2020. URL : http:// journals.openedition.org/msh/2729; DOl : https://doi.org/10.4000/msh.2729

Ce document a été généré automatiquement le 23 juillet 2020

(C) École des hautes études en sciences sociales 


\title{
Les problèmes de la statistique
}

\author{
The problems of statistics
}

\section{Georges-Théodule Guilbaud}

\section{RÉSUMÉS}

Le texte qu'on va lire est une réimpression du Chapitre VI du Traité de Sociologie (tome premier), publié en 1959 aux Presses Universitaires de France sous la direction de Georges Gurvitch. Celuici était en effet assez convaincu de l'importance de la Statistique dans sa discipline pour vouloir qu'une présentation en soit faite dans son Traité. On verra que le parti pris par G. Th. Guilbaud fut non de décrire des techniques de la Statistique en vogue chez les sociologues de cette époque (comme par exemple, le test du Khi-deux ou l'Information de Shannon, comme indicateur du degré d'indépendance entre deux variables), mais de s'efforcer de faire comprendre l'esprit des méthodes statistiques, et leur généralité : ce qu'indique bien le titre du Chapitre : "Les problèmes de la Statistique". Il en est résulté un texte tout à fait remarquable et qui, comme on dit "n'a pas pris une ride" quelque quarante ans après avoir été écrit et dont tout utilisateur ou praticien de méthodes statistiques (peu importe que ce soit en Sociologie ou dans une autre discipline) peut encore faire son profit. C'est pourquoi le traité de G. Gurvitch étant depuis longtemps introuvable, il a paru opportun à la rédaction de Mathématiques, Informatique et Sciences humaines de le mettre de nouveau à la disposition des lecteurs.

This paper is a reprint of the chapter VI of the Traité de Sociologie, edited in 1959 by G. Gurvitch and published by the Presses Univerrsitaires de France. In this paper, G. Th. Guilbaud tries to make clear the spirit of statistical methods and their generality. This quite remarkable text is not at all out of date 40 years after ; every one who is practising statistical methods will be able to profit by it. 
INDEX

Thèmes : histoire des mathématiques, pédagogie, statistique, épistémologie 